\title{
Depictions of nursing home residents in US newspapers: successful ageing versus frailty
}

\author{
JULIA ROZANOVA*, EDWARD ALAN MILLER $\dagger$ \\ and TERRIE WETLE $\$$
}

\begin{abstract}
The media shape both what people consider significant and how people think about key issues. This paper explored the cultural beliefs and stereotypes that underlie media portrayals of nursing homes. The analysis of texts of 157 articles about nursing homes published from 1999 to 2008 on the front pages of four major-market American newspapers (The New York Times, Chicago Tribune, Los Angeles Times and The Washington Post) was conducted using a qualitative approach inspired by comparative narrative and critical discourse analysis. Results suggest two major themes, each with several narrative components: (a) managing disposable lives (bodies outliving bank accounts; making frailty affordable; and the economics of triage); and (b) retaining purchasing power as successful ageing (consumption as a sign of market participation, spending money as an indicator of autonomy; and financial planning as preparation for future decline). Thus, the results indicate that nursing home residency in-and-of-itself is not a marker of unsuccessful ageing. This, instead, depends, in part, on the extent of choice available as a result of the level of financial solvency. This study shines light on the betwixt and between zone that distinguishes the Third and Fourth Ages; that is, independence versus dependence in old age. If individuals in a nursing home retain control over the management of their lives through the maintenance of financial independence, even if physically frail, association of nursing home residence with the Fourth Age may be ameliorated.
\end{abstract}

KEY WORDS-American nursing homes, newspaper portrayals, qualitative analysis, financial insolvency, market participation.

\section{Background}

The media have a two-part agenda-setting role: they shape both what issues people consider significant and how people think about these significant

* Department of Sociology, Yale University, New Haven, Connecticut, USA.

$\dagger$ Department of Gerontology, McCormack Graduate School of Policy and Global Studies, University of Massachusetts, Boston, USA.

\$ School of Public Health, Brown University, Providence, Rhode Island, USA. 
issues (Blakemore 2012; Miller et al. 2012). When depicting older adults is deemed newsworthy (which is not very often, as later life and its issues are generally under-represented in the media), the media tend to focus on the 'younger old' and emphasise their self-responsibility for staying healthy, active and engaged as long as possible, rather than on the 'older old' (Laliberte Rudman 2006; McHugh 2003). In the language of the numbered lifecourse stages, in representing later life the media have focused on the Third Age associated with retirement and characterised by freedom of lifestyle choices and pursuit of self-oriented goals like travelling, acquiring a new hobby or learning new things (Gilleard and Higgs 2011 ; Laslett 1996), but considerably less on the Fourth Age associated with decline and death. One reason for this may be what Walter Benjamin identified in his 1936 essay 'The work of art in the age of mechanical reproduction' as an effort to enable people to avoid the sight of the dying, pushing it further from the perceptions of the living, with, for example, end of life and dying taking place in nursing homes, far removed from the public eye.

Thus when the media occasionally bring nursing homes and issues associated with them to the public eye, it is particularly fascinating to understand what these stories mean. To the best of our knowledge, there have been few studies to date that examine how nursing homes are portrayed in the media (Mebane 2001; Miller et al. 2012; Ulsperger 2002). One such study examined media coverage of programmatic changes and legislative reforms in the 1980 os and 1990 os (Ulsperger 2002), suggesting that media framing of nursing home care affected the senior rights movement and led to the formation of the National Citizens' Coalition for Nursing Home Reform. A more recent study examined how the media portrayed reasons for nursing home closure (Fisher and Castle 2012: 412). No study has focused on the meanings that media portrayals may convey about nursing home residents.

The media interest in depicting nursing home scandals and their relationship to public action and to government regulatory response spiked in the aftermaths of hurricanes Katrina and Rita that claimed the lives of many nursing home residents. Taking those events as an inspiration, we conducted the first (to the best of our knowledge) systematic comprehensive study of newspaper portrayals of nursing homes in the United States of America (USA). There were two goals. First, we sought to understand and represent how nursing homes are depicted in the mass media. Second, we sought to understand how these depictions fit within the extant literature on media portrayals of later life, which range from frailty and dependence to successful ageing (Kessler, Rakoczy and Staudinger 2004; McHugh 2003; Whitfield 2001). The first phase of our study focused on periodic treatment of topic and tone in articles pertaining to nursing homes, where we outlined 
when and how the media write about nursing homes (Miller et al. 2012). Using a systematic keyword search technique, we identified and extracted 1,704 articles that focused on nursing homes and their issues published in The New York Times, The Washington Post, Los Angeles Times and Chicago Tribune over a period from 1999 to 2008, and conducted a quantitative content analysis of these articles. These papers were selected because of high circulation levels and geographic coverage. The results suggested that the tone of media coverage of nursing homes has been predominantly negative, sometimes neutral and rarely positive. The issue of quality of care was discussed most frequently during the period studied, while financing peaked in 1999-2002 (at the time of the discussions of proposed long-term care reforms), negligence/fraud peaked in $2003-07$ and natural disasters peaked dramatically in $2005^{-06}$.

These findings revealed the overall dynamics of tone and main topics of newspaper coverage of US nursing homes. They also suggest that in-depth qualitative analysis of a sub-sample of articles is necessary to produce a more nuanced understanding of the topics explored. This paper describes the second phase of our study, where we use qualitative analysis of all articles about nursing homes published on the front pages of the four newspapers analysed during the time period studied to identify, assess and represent 'what cultural stereotypes and values underlie the ways in which newspaper articles speak about and portray nursing home-related issues' (Miller et al. 2012: 751). We begin with a brief review of successful ageing as cultural background for understanding media portrayals of later life (Rozanova 2010 ), followed by a description of methods. Then we present our findings, discuss them in the context of the extant literature and address our study's implications for the public's understanding of long-term care issues.

\section{Successful ageing as a cultural phenomenon}

Population ageing is a key social challenge of our time. As governments strive to reduce the costs of elder-care in the context of a decreasing population of younger people entering the workforce, successful ageing has become a popular concept that refers to simultaneous reduction of disease and disability, maintenance of cognitive and physical functioning, and active social engagement throughout the lifecourse and into later life (Rowe and Kahn 1998). The academic literature on successful ageing includes a critical stream that points out substantial controversies in both the concept and in the way it may be applied. The first serious criticism is focused on the definition of criteria for 'success' in the process of ageing, and who, and on what grounds, may legitimately claim the authority to provide such criteria 
(Bowling 2007; Minkler and Fadem 2002). It is emphasised that values of independence, productivity and youthfulness of the body, that constitute the core of the successful ageing ideal, are characteristics of contemporary capitalist societies that do not reflect the attitudes and values prevalent in other cultures (Bowling 2007). Moreover, constructing a definition of 'successful' ageing may devalue and negatively impact the wellbeing of people whose lives and lifestyles differ from the ideal (Chapman 2005). Although societal constraints may provide individuals with limited or no choice in terms of the lifestyle they pursue, say, due to discrimination on the basis of gender, race or social class, the notion of successful ageing places responsibility to age successfully on the individual, blaming the victims for their shortcomings (Moody 2008).

Linking positive outcomes to active engagement of older adults in predominantly unpaid productive activities such as volunteering does not account for seniors whose safety nets have been weakened by withdrawal of both state and market mechanisms for ensuring social and economic security in late life (Martinson 2007; Martinson and Minkler 2006). Downloading responsibility for providing security to individuals themselves ignores both life-long experiences of exclusion and marginalisation in the context of the market economy of persons who in later life fail to age 'successfully', and the fact that such individuals are most likely to live in disadvantaged communities (Holstein and Minkler 2003). Instead of providing a backdrop for, say, the consumption of various anti-ageing products and services, these communities rely heavily on the work of ageing members for survival (Rozanova, Dosman and de Jong Gierveld 2008).

For its part, the mass media compare and contrast older persons against one another in terms of how successfully they are ageing (Laliberte Rudman 2006), using such markers as maintaining one's youthful physical appearance and one's active social engagement (Chivers 2008; Rozanova 2010). The popularity of successful ageing in the media is sustained by both cultural and pragmatic reasons (Chivers 2007). Because ageing baby-boomers constitute the largest and most lucrative consumer market with the highest purchasing power (Sinding and Gray 2005), the mass media spearhead an elaborate cultural campaign to sensitise them to the pleasures of successful ageing (Gilleard and Higgs 2007; Hilt and Lipschultz 2005). This is reflected in media portrayals that glorify successful ageing and provide blueprints for how individuals should behave throughout their lifecourse in order to age well, including detailed recipes for managing various aspects of one's family, social, economic and civic life (Laliberte Rudman 20o6; Rozanova 2010). These blueprints divide later life into the Third and Fourth Ages with the cultural process of successful ageing effectively embracing the former but not the latter (Gilleard and Higgs 2007). 
The interest in distinguishing between the Third and the Fourth Ages stemmed from the rise in life expectancy and the need to specify the heterogeneity of older adults in terms of mortality, morbidity, health-care needs, quality of life and social engagement (Pifer and Bronte 1986). The Third Age is usually associated with retirement from a job, and Third Agers have been described as individuals who enjoy good health and personal achievement and fulfilment through active social engagement (Laslett 1996; Neugarten 1974). Adjacent to midlife, the Third Age is thus characterised by staying active, youthful and independent (McDaniel 2005). The criterion of youthfulness for Third Agers is to be perceived as indiscernible from middle-aged individuals in terms of their physical capabilities, economic resources, social capital, location within the status and power hierarchy, and general lifestyle (McDaniel 2005). The media glorify the Third Age as a consumer's paradise achievable through an individual's personal responsibility for choosing an appropriate lifestyle (McHugh 2003). In contrast, Fourth Agers have been described as those persons for whom it is typical to experience all the negative and adverse events stereotypically associated with old age and sliding downwards into irreversible loss and decline - decline of physical and mental alertness, disease and disability, loss of independence, loss of income, loss of social and economic power and status, loss of social relationships and eventually loss of life (Gilleard and Higgs 2010). What events determine transition from the Third Age to the Fourth Age has been debated, but entering a nursing home may be plausibly viewed as a transition to the Fourth Age, as individuals enter nursing homes when they become frail and unable to live independently and care for themselves.

Newspaper and magazine articles, television advertisements, posters and even books suggest that to live healthily and happily well into advanced old age an individual must be a smart consumer who makes informed choices about purchasing and utilising appropriate products, from cosmetics to organic foods to fashionable clothes to gym memberships to Caribbean cruises (Chivers 2003). The mechanism for remaining in the Third Age advertised by the media is the healthy lifestyle that rests on two pillars: active social engagement in economically productive activities including unpaid volunteer work or, less commonly, paid employment, and consumption of anti-ageing and youthfulness-boosting products that range from food to skin and body care to clothes to fitness to leisure (Gilleard and Higgs 2007). The quest for successful ageing resembles an endurance contest - the longer Third Agers are able to hold on to their youthfulness and not slide into the Fourth Age, the more successful they are (in contrast to their peers) (Gilleard and Higgs 2010). In this respect the media present abundant successfully ageing role models selected from both ordinary citizens and well-known politicians, businesspersons or popular culture stars 
(Laliberte Rudman 2006; McHugh 2003; Rozanova 2010). Throughout this celebration of agelessness and the postponement of mortality through smart consumption, the Fourth Age and impending decline and death lurks, demonised and shunned (Gilleard and Higgs 2011 ; Jopp, Rott and Oswald 2008). Fourth Agers are pitied yet avoided as 'them and the ultimate other' who are different from 'us' (Bytheway 2005). Those in the Fourth Age but not yet among the oldest old are openly or tacitly judged for having made substandard choices in terms of their lifestyles and attitudes that - perhaps aided by the environment where they had the misfortune to live - have led to their failing the quest for successful ageing.

Previous research that has focused on various aspects of successful ageing suggested that behaviours such as staying active and engaged and preserving a youthful body are established cultural norms by which older adults assess how they are ageing in comparison to their peers, and by which others in society assess them (Tulle 2008). The cultural process whereby successful ageing has become a powerful and potent normative ideal is actively promoted in the media and simultaneously addresses the profound human fears of mortality and the economic realities of the early twenty-first century. Successful ageing, which is equated to remaining in midlife as long as possible, serves to postpone, if not altogether eliminate, death from individuals' radar screens. Simultaneously, ageing baby-boomers have significant market power; successful ageing is a powerful ideal that makes anti-ageing products and services attractive for middle-aged individuals (Sinding and Gray 2005).

The normative scripts for successful ageing presented in the media are not only ageist in that they divide older adults into 'us' and 'them' in terms of how successfully they are ageing, but also have a gender bias (Hatch 2005 ). For women, successful ageing constitutes the preservation of their youthfulness and beauty, their social roles as being romantic partners, their economic roles as viable consumers and their community roles as carers for other persons (Spector-Mersel 2006). For men, successful ageing constitutes sustaining their sexual prowess as well as economic and social status in the marketplace and community (Thompson and Whearty 2004). Men's physical youthfulness, though important, is not as central for the successful ageing script as it is for women, while ageing men's place in the hierarchy of power that determines their ability to make decisions takes precedence (Turner 1991). Previous research has noted that both men and women with higher social and economic status were less likely to be referred to as being 'old', in contrast to their less socially and economically solvent peers (Rozanova, Northcott and McDaniel 2006).

We have argued elsewhere (Rozanova 2010) that similar to the notion of polarised ageism (McHugh 2003), whereby older age is divided into positive 
and negative extremes, the theme of successful ageing in the media is also polarised. In addition to examples of successfully ageing role models, media texts present their antitheses, describing individuals who manifest various signs of physical, social and economic decline. This raises the question of how far the discourse of successful ageing goes in terms of providing recipes for agelessness, who is excluded from the successful ageing cultural discourse and what it means in the context of a market economy. This paper addresses these questions by considering media texts about individuals who, on first glance, have dramatically failed the quest for successful ageing persons residing in long-term care institutions (i.e. nursing homes). Nursing home residents have substantially higher burdens of disease and disability in comparison to the rest of the population, have diminished physical and/or cognitive function, and have compromised social engagement by the very fact of residing in an institution. Our results demonstrate that despite such characteristics, the media does indeed represent certain segments of the nursing home population as having aged successfully.

\section{Methodology}

\section{Data}

All articles on nursing homes published in four leading national newspapers - The New York Times, The Washington Post, Chicago Tribune and Los Angeles Times - from 1 January 1999 to 31 December 2008 were retrieved by eight trained research assistants from the complete, commercial version of the LexisNexis database. A ten-year period was chosen to identify durable cultural trends in media portrayals of nursing homes while avoiding the risk of portrayals being overly affected by one specific policy change or event. The New York Times, The Washington Post and Los Angeles Times were chosen because, at 876,638,6oo,449 and 545,345, respectively, they are among the top five most circulated dailies in the USA (Audit Bureau of Circulations 2010). The Chicago Tribune was chosen to ensure more balanced regional representation; at $44^{1,508}$, it is the most circulated newspaper outside California and New York.

The following search terms were used: 'nursing home' / nursing homes', 'long-term care facility'/'long-term care facilities' and 'nursing facility' / 'nursing facilities'. Each article was screened for potential relevance. Those excluded from the final sample consisted of duplicates (including news briefs), obituaries, advertisements, and articles that were not about nursing homes but mentioned nursing homes in passing or were about another topic (e.g. reporting on a local election site). Of approximately 5,ooo articles identified, 1,704 were deemed relevant. 
The data used in this paper comprise 157 articles published on the front pages of the newspapers analysed. These articles may be viewed as the flagships of discourse about nursing homes during the time period studied. Cover-pages of major newspapers symbolise the newsworthiness of topics and events: being on the front page of The New York Times, for example, means being important news, and, as such, may have a disproportionate impact on how the public thinks about the issues represented. Thus, in light of our goal to understand what meanings and stereotypes underlie media depictions of nursing homes, analysing front-page articles about nursing homes is particularly relevant.

\section{Data analysis}

Analyses were conducted using a qualitative approach inspired by comparative narrative and critical discourse analysis (Atkinson 2010; Fairclough 2010). Narrative analysis focuses on understanding stories which people (such as columnists) or social institutions (such as the media) use to interpret the world (Atkinson 2010). Stories, or narratives, are considered social products created in specific socio-cultural conditions. People use them as interpretive devices, both to give meaning of the world and to represent this meaning to themselves and to others (Phoeniz, Smith and Sparkes 2010). Critical discourse analysis focuses on the role of language and text in building and sustaining power relations through the (re)production of dominance in its different forms and ways of representation (Fairclough 1995, 2010; Fowler 1991; van Dijk 1997, 2006).

Both methodological traditions - discourse and narrative analysis - share a constructionist and interpretative way of considering stories as products of relationships among social groups, elites and institutions, in the context of social, political, cultural, gender and other kinds of inequality (van Dijk 2006). Both aim to look beyond the surface of stories (narratives, or discourses) in order to understand the power relationships and inequalities that shape these stories. Thus, we sought to glean insights into ways in which the articles portrayed nursing homes and their residents, and to interpret our emerging understandings in light of the institutional context of concerns for the costs of elder-care and sustainability of the long-term care system, and in light of the narrative context where discussions about successful ageing is a key topic for both researchers and the media. It is noted that the authors and the student research assistants who helped with data collection included both male and female researchers of different generational cohorts, thus helping us to glean a variety of insights on what the articles could mean from different points of view. 
The first and second authors began the analysis by reviewing previous studies examining how specific issues have been portrayed in the media (e.g. Baumgartner and Jones 1993; Laliberte Rudman 2oo6; McHugh 2003), in order to ensure that our analyses searched beyond what is already known, to watch out for the unexpected and the surprising. Next, the first author read the texts of the nursing home articles identified, paying attention to initial impressions about the ideas that each article was conveying individually, and to the story or stories that the articles as a group were conveying collectively. This was an inductive process of identifying and reflecting on the main story and its narrative components in one article, considering if and how another article added to or contradicted this story, and recording these reflections as memos, adding new thoughts or refining them as the reading of articles continued. Pieces of text that exemplified narrative components of the stories identified were coded as categories, that is, the first author attached labels that served to group similar excerpts of text. Once an initial structure of categories was developed, the first author re-read the articles, looking for disconfirming cases and considering alternative interpretations. To ensure the rigour of the analyses as they progressed, the first author met bi-weekly for four months with the eight research assistants who had collected and read through all the data to discuss emerging themes, to consider whether they made sense in light of other individuals' reading, and to develop the most meaningful labels to capture and reflect accurately the content of the data from which it had been synthesised. At the end of this process the first author shared with the other authors her understanding of the articles and this understanding was refined through subsequent discussion, and in some cases we split categories and in other cases we merged categories, all in order to more accurately describe the articles' narrative components. Finally, all the authors considered the general storyline(s) that the articles told collectively about nursing homes, which we call themes.

\section{Findings}

We elucidated two key themes underlying stories about nursing homes published on the front pages of the four major-market American newspapers over the ten-year period analysed. These are 'managing disposable lives' and 'retaining purchasing power as a form of successful ageing'.

\section{Theme one: Managing disposable lives}

Not surprisingly since scandals make stories newsworthy (Wetherell, Taylor and Yates 2001), if an article about nursing homes made the front page it 
almost always was an 'Oh My God!' story that focused on the outrageous (lack of) care provided to the frail dependent elderly people residing in those facilities. The first major theme, 'managing disposable lives', refers to how the system of long-term care commodifies frail human bodies to manage them. While the initial reaction these stories provokes is pity for the victims and outrage for the way they were treated, our interest was in getting beyond the emotional surface to understanding the reasons underling these horrific portrayals and what messages about status, power and inequalities they implicitly convey. Three narrative components through which the theme 'managing disposable lives' was manifested are: 'bodies outliving bank accounts', 'making frailty affordable' and the 'economics of triage'.

Bodies outliving bank accounts. The 'bodies outliving bank accounts' narrative component focuses on how the biological lives of older persons may be asynchronous from their social and economic lives. While their economic lives may have already come to an end and the material resources they once possessed fully depleted, the physical lives of elderly nursing home residents is not yet over:

Thanks to medical advances worldwide, the average life expectancy has increased [and] now, it's almost 8o. During the 1990 alone, longevity increased by five years. But making sure that these years are free of disability and disease is another matter, especially when bodies can outlast brains, support systems and bank accounts. ('Ageing “kids" join parents in nursing homes', Chicago Tribune, 2 May 1999)

On one hand, this excerpt is reminiscent of the long-standing 'grey tsunami' discourse that has been noted in previous research (McHugh 2003), whereby population ageing as a phenomenon and the increasing proportion of older adults in the structure of the population are considered a challenge due to fears of how the systems that support the needs of this population, including but not limited to pension plans and medical insurance, may be financed.

The 'grey tsunami' discourse, however, points to inter-generational inequalities between older and younger people whereby the latter must, presumably, bear the costs of supporting the former (Rozanova, Northcott and McDaniel 2006). In this respect, all older people, in mass, are a tsunami that carries the potential of demographic and economic catastrophe. In contrast, the 'bodies that have outlived their economic life' narrative individualises the issue, differentiating among older adults of different kinds. The emphasis shifts from the general concern about societal costs of population ageing, towards locating the source of concern within a very select group of older adults and, ultimately, within select individuals who have particular characteristics and presumably have behaved in a particular 
way to result in such a state of affairs. Rhetorically, this is done by bringing to the forefront the possibility that specific individual bodies may outlive their own bank accounts and support systems. The excerpt is rife with indirect references to intra-generational inequality as only some bodies outlast brains, support systems and bank accounts. The rest of the article focuses on ways to avoid this lack of synchronicity between one's biological and economic lifetimes through individual efforts and careful advance planning for one's financial solvency in later life.

The challenges posed by 'bodies outliving bank accounts' is particularly salient for older immigrants, who often do not have private health insurance, savings and family support, nor qualify for public programmes. Hospitals and nursing homes seek to avoid such patients wherever possible lest they become a burden:

Mr. Yu, 53, suffered a stroke on May 14, 2007 ... One day last summer, he lay in his fourth floor bed watching a soundless 'Clifford the Big Red Dog' cartoon with his roommate, a tiny, elderly Chinese man who has been boarding at the hospital for years. According to a hospital document, he is 'dependent on staff for daily necessities' and suffers from 'limited cognition and limited independent judgment.' But since he was uninsured and ineligible for Medicaid [public insurance], no nursing home would take him. He had no relatives in the United States. ('Deported in coma, saved back in the US', The New York Times, 9 November 2008)

The article went on to describe the details of complex negotiations between the hospital and the nursing home, through court-appointed lawyers, of cases like Mr. Yu and other frail individuals who, though old enough and financially eligible for [public programmes], lacked coverage for their complex and expensive care needs due to their immigration status. In this case, the hospitals and the nursing homes tried to manage the lack of synchronicity between biological and financial life of a body by dodging frail and insolvent patients, or trying to make them somebody else's problem.

Making frailty affordable. What may be done about individuals whose bodies have already outlived their bank accounts? In most market economies, it becomes the collective responsibility to manage the care of frail elderly whose physical bodies have benefited from increased longevity, but who have arrived at advanced old age with disease and disability, and without personal resources in place to provide for their own care. In other words, society must find solutions to managing frail and poor elders in a way that is costeffective and affordable. This second narrative component of the 'managing disposable lives' theme, 'making frailty affordable', was particularly prevalent in years during which active discussion and/or passage of legislation concerning long-term care financing were under way; 1999 being a case in point when various proposals to restructure health and long-term care payment systems were under consideration. 
Articles in this vein critiqued the commercialised system of long-term care financing and service delivery with its emphasis on maximising returns and minimising costs. Yet the articles also took for granted the comparative powerlessness and lack of privilege of frail individuals with insufficient resources to finance their own care. Whether within long-term care institutions or in a broader societal context, they were no longer active subjects with a recognised agency to make decisions. They were portrayed to be the objects and the recipients of decisions made by others who commanded resources that frail, dependent older persons lacked. As individuals with complex needs, but little income and few assets, the frail older adults portrayed in these articles could not act themselves, they were being acted upon. This meaning was reinforced through the choice of the passive voice, like in the following excerpt:

Many elderly and disabled patients are being shut out of nursing homes because a new restrictive Medicare payment system has prompted facilities to shun those with costly medical needs ... The shift in payment methods, required by the Balanced Budget Act of 1997, is part of a federal effort to keep Medicare from collapsing under the financial burden imposed by the ageing of the baby boomers. ('Nursing homes shun some Medicare patients', The Washington Post, 7 June 1999)

While the frail populations portrayed in the article have the sympathy of the storyteller, it is taken for granted that they are a burden, the passive recipients of resources that a benevolent society may provide to pay for their care. They are shown to have no decision-making voice, no position to articulate their interests and needs, and thus effectively excluded from the rights of full citizenship. These frail individuals' past contributions to the economy or public purse are not part of the picture; what matters most is the presence or absence of resources at the present time. As their own resources are non-existent or meagre, they are shunned by commercialised segments of the long-term care system, while the society struggles to sustain medical insurance and other social supports in the face of rising health-care costs and a changing population structure.

The economics of triage. Some articles about the aftermath of hurricanes Katrina and Rita in the mid-2ooos had a provocative and disturbing discussion of principles for allocating scarce and precious resources to individuals who are too frail to claim these resources themselves. The stories reported contained gruesome portrayals of how frail individuals in the care of nursing homes were essentially left to die when they were assessed as unlikely to survive during evacuation. The scarce availability of life-saving resources in the face of natural disaster most vividly suggests that the lives of some nursing home residents become virtually disposable. In these stories, the lack of physical resilience and limited remaining life expectancy was 
depicted as a certain moral justification for decisions about who to rescue and who to leave behind.

Triage meant making decisions about who was likely to live and die, and Shatz [the rescuer flying a Black Hawk] figured there were more [decisions] to be made. To his surprise, the nuns [who ran the nursing home] had largely done the sorting for him. The first patients at the top of the stairs were the fittest. Down the hall, they seemed progressively weaker. ("At nursing home, Katrina dealt only the first blow', The Washington Post, 23 September 2005).

Particularly concerning is the need to make such decisions in the first place. In a circumstance where there are not enough resources to take care of all citizens at times of crisis, nursing home residents are particularly vulnerable and may be subject to competition for the status of the likeliest to survive. While it went without saying that all the inhabitants of nursing homes were quite frail, they were still judged in terms of the relative severity of their disease and disability and the degree to which environmental conditions exacerbated their frailty. As resources were not deemed sufficient to rescue all nursing home residents incapable of making their own self-preservation efforts, preference was given to those deemed by others as most likely to survive. Furthermore, as stories noted, these were corporate and private rather than public decisions, and nursing homes differed in their ability and willingness to spend financial resources for organising evacuation campaigns, as the three excerpts below illustrate.

Some nursing homes spent as much as $\$ 5^{\circ}$,ooo to move their patients to safety, including using private helicopters. ('More deaths confirmed in homes for the aged', The New York Times, ${ }_{5}$ September 2005)

Unless the hurricane is coming in my back door, I'm not putting my residents through an evacuation and wasting money. ('Nursing home owners acquitted in Katrina deaths', The Washington Post, 8 September 2007)

When you make a decision over life and money, you've got a problem. They wanted to take a chance, and they took a chance on the wrong storm. ('Katrina's aftermath: haven turned to horror', Los Angeles Times, ${ }_{4} 4$ September 2005)

The valuation of human life is present in the stories reported. While a society's ethical foundations may be revealed in how it treats its most vulnerable members, financial considerations were explicitly used to evaluate the worth of frail elders during the course of the hurricanes. The stories revealed how having a negative individual difference (i.e. comparative disadvantage of persons who are frailer and thus less likely to be considered as viable candidates to be rescued) is compounded by inequality among facilities, in terms of resources their management could or chose to allocate to evacuate or to shelter in place. However, it is significant that the articles 
took it for granted that the responsibility for making decisions about allocating resources to evacuate or to shelter belonged to individual facilities rather than the broader society within which they were situated. Thus, the articles attributed blame for failing to conduct the rescue missions, or praise for conducting them well, to specific nursing home operators or health-care workers.

Heroic efforts by doctors and nurses across the city prevented the toll from being vastly higher. Yet the breadth of the collapse of one of society's most basic covenants - to care for the helpless - suggests that the elderly and critically ill plummeted to the bottom of priority lists as calamity engulfed New Orleans. ('Vulnerable, and doomed in the storm', The New York Times, 19 September 2005)

As we have seen so far, stories about human frailty in the context of nursing homes revolve around the theme of how affordably and cost-effectively others can manage the lives of individuals who are no longer in the position to do so themselves. This theme resonates with the idea of the Fourth Age as the time of ultimate decline at the end of life, and seems to be in contrast to the notion of successful ageing referred to earlier. Thus, narrative categories associated with the Fourth Age, such as dependence and obsolescence, were prevalent in the stories reported, though further analysis suggests that not all nursing home residents are described as Fourth Agers in the national media. This leads to the second theme identified in this analysis.

\section{Theme two: Retaining purchasing power as successful ageing}

The second major theme relates to how nursing home residents themselves are viewed. Separate categories of nursing home residents are depicted in different ways in the stories reported. This suggests that nursing home residency in-and-of-itself may not be the most significant symbolic marker of unsuccessful ageing, or moving into the status of the Fourth Age. Indeed, the discourse of successful ageing appears in stories that on first reading could be seen as being all about the Fourth Age. However, there are subtle but crucial distinctions made between nursing home residents who, on the one hand, may be viewed as clearly belonging to the Fourth Age (i.e. those who no longer can manage their own lives) and nursing home residents who are still in the Third Age (i.e. those who retain a significant degree of control over their lives).

Residents who retained their purchasing power could buy goods and services, which meant that their participation in society extended beyond the walls of the nursing homes within which they lived. Their institutionalisation was not portrayed as complete. In contrast to frail and dependent elderly 
who no longer managed this or most other aspects of their lives, the ability to interact as economic agents with the world outside meant that at least some subset of institutionalised elders retained some autonomy and therefore a key characteristic of the Third Age. Thus, another way in which articles depicted nursing home residents emphasised maintenance of purchasing power as a sign of successful ageing, achieved through market participation. Three narrative components through which the theme 'retaining purchasing power as successful ageing' was manifested were: 'consumption as a sign of market participation', 'spending money as an indicator of autonomy' and 'financial planning as preparation for future decline'.

Consumption as a sign of market participation. The first narrative component of the theme 'retaining purchasing power as successful ageing' was a portrayal of informed, active, resourced and decisive individuals who maintain their capacity to make and implement decisions about their care and their day-to-day life. Examples newspapers provided were not so much of current, but of future nursing home residents - particularly of various groups of ageing baby-boomers, and ways in which their generation is expected to be different from the current generation of nursing home residents. As these individuals will eventually start to experience the disabling consequences of their diseases and transition to long-term care, they will still remain their autonomous, empowered selves, furthermore, references to their economic power suggested they will be able to purchase care privately and thus choose what they want, instead of depend on Medicaid:

One man - a retired teacher who developed Parkinson's disease - went to live in an assisted-care home and found that he was the only gay man there. He felt his care would be compromised if they knew. But while homosexuals his age see special retirement housing as something akin to a dream, those of the baby-boomer generation will demand that kind of retirement, some experts say. And those who helped create thriving gay communities in American cities will insist on living that way, if at a somewhat slower pace, in retirement, say developers in Boston, Fort Lauderdale and other cities. 'It's a healthy phenomenon,' said Mr. Golant, who sees plans for the developments as proof that a generation of homosexuals have the social and economic power to carry it off ... Living there will not be cheap. Buyers will pay $\$ 235$, ooo or more for one- and two-bedroom apartments, and a monthly fee of $\$ 2$, ooo to $\$ 4$,ooo, depending on how much care the resident needs. Besides a nursing staff and in-house health care, the high-rise will have its own theater, where independent films could debut; its own art gallery; a market with specialty foods, and restaurants. ('Fearing isolation in old age, gay generation seeks Haven', The New York Times, 20 October 1999)

Although retired and increasingly frail, as long as they have money in their purse and retain control over their purse strings, older adults remain important participants in the nursing home industry. Other actors of the 
market economy will take into account and respond to their wishes and desires. It is worth stressing that this economic participation was only possible in the presence of adequate financial resources that the articles emphasised. An earlier quote from the story about less well-off and demented nursing home residents made explicit the financial disadvantage of older adults who had outlived their bank accounts and their brains. Stories about better faring nursing home residents did not mention a dearth of economic resources. On the contrary, the articles either emphasised financial resources needed to obtain this care explicitly, or alluded to residents of higher social status who could, for example, be retired professionals, or had retained the skills necessary to articulate their needs and interests in a way that could be heard and acknowledged.

Individuals who continued to be a market participant were presented as an emerging or new type of resident in the context of media portrayals. Although either already frail and disabled or on a definite trajectory leading there, this new breed of resident was portrayed as nearly equal to their community-dwelling, successfully ageing counterparts from an economic standpoint.

Spending money as an indicator of autonomy. The articles portray the boundary between the Third and the Fourth Agers as a fine balance between autonomy and dependency, autonomy manifesting in the continued ability to manage one's own life through spending money. This ability puts residents into the privileged category of those who are frail but still retain autonomy and thus have some life left in them, in the financial as well as in the physical sense. Thus, the articles suggest that continued financial solvency keeps some nursing home residents in the position of active and autonomous agents. Older adults in nursing homes retain autonomy of their decision-making by remaining consumers of goods and services for which they pay their own money.

To satisfy active seniors who don't want to live in traditional nursing homes ... St. Edmund's Tower, for instance, has a wellness centre, library, community room, and transportation to area stores ... Loretta Scheiwe is planning to walk to the beauty school in a nearby shopping centre. She feels like she still has her freedom. ('Longer lives, changing notions have senior housing growing with vim and vigour', Chicago Tribune, 14 March 1999)

Being able to spend money is portrayed as autonomy, and having money to spend makes one an active senior, with freedom to decide what to buy, in the context of choices carefully selected and offered by the economy and its players who recognise the power of the gold in grey. Yet in the above quote, the reference to 'traditional nursing homes' is the reference to a stereotype, an implicit portrayal of a non-active senior, who has no freedom to manage 
their life. As Gilleard and Higgs (2007) pointed out, ideas of the Third Age revolve around the issue of (re)-defining oneself through careful consumption; in the data analysed, control of one's life is equated with freedom to buy products and services.

Financial planning as preparation for future decline. The third narrative component of the theme taps into the issue of individual responsibility for how successfully one is ageing. It is emphasised that responsible citizens should financially plan for their decline ahead of time, not wait until they outlive their bank accounts, leaving themselves at the mercy of social care institutions. Financial planning for one's decline is presented as a form of a savings account that creates a reserve of not only money but also of purchasing power that is stored for future use, a reserve of individual's agency that is crucial for the ability to age successfully.

While proximity to mom was a plus for the Bredemeiers, it was not the focus for their move to the complex, situated on 55 bucolic acres. It was their desire to have a blueprint for the future. 'We feel so smart,' Bill says. 'We can come and go as we please - just lock the door and go to Florida whenever we want. We're really active now, but if our health deteriorates, we're in good hands. ('Ageing "kids" join parents in nursing homes', Chicago Tribune, 2 May 1999)

Simultaneously to ensuring their ability for being in control, responsible citizens alleviate society from the pressures of having to manage their lives, say by paying for their care, should they eventually become physically dependent and frail. The articles praised this kind of financial planning where the individuals scrimped and saved during their working life to spend their hard-earned money on their later-life care. On the other hand, the articles vilified affluent seniors who could afford but avoided paying for their care, instead engaging in clever and careful financial planning with the help of the lawyers to circumnavigate the system and to secure various benefits from the public purse, while disadvantaging 'truly poor' seniors whose care should be covered by the state. The articles criticised wealthy seniors for using various tax and insurance loopholes to transfer their assets, secure inheritance for their children and qualify for state assistance in nursing home care, avoiding out of pocket expenses:

At a tremendous cost to taxpayers, aging Americans in California and across the nation are transforming themselves, at least on paper, from affluent seniors to needy individuals eligible for state health benefits ... At the Pilgrim Haven Retirement Community's nursing home in the affluent San Francisco suburb of Los Altos, the staff was baffled when a patient with a $\$ 2$-million house, pricey commercial property in San Jose and considerable savings recently became eligible ... 'There is an entire industry around the country set up to coach people to transfer their assets to their children, so the state can pay for their care,' Scully said. 'Every time you pay for one of these people to go to a nursing home, you are taking money away from the people 
who are truly poor.' ('The state; Public pays for wealthy seniors' care: Loopholes let the well-off transfer assets on paper in order to receive aid', Los Angeles Times, 2 May 2004)

In sum, the second theme points to the other end of the polarised binary whereby media articles portray nursing home residents. In contrast to the completely frail individuals with no control over their lives who are managed by the people who provide care for them (but not always care about them), this theme depicts autonomous residents who are still ageing successfully despite their frailty, by delegating tasks of their care to professionals while retaining control over the management of their lives through participating in the market economy, and making all financial decisions about their care. This theme extends the possibilities of successful ageing from its usual place in the community to long-term care institutions. In so doing, it suggests that nursing homes need not be populated entirely by 'the other' whose lives we can only manage (i.e. those in the Fourth Age), but that there are also those who are like, or almost like, us (i.e. still in the Third Age).

\section{Discussion}

By Rowe and Kahn's (1998) definition, persons who go to a nursing home have failed to age successfully. Yet the main contribution of this study is in shining light on the betwixt and between zone that distinguishes the Third and Fourth Ages, adding to the work of those who have written about successful ageing discourse in the context of media portrayals (Laliberte Rudman 2006; McHugh 2003). Previous research suggests that the Fourth Age is separated from the rest of the lifecourse as a time of decline, loss of agency and death (Gilleard and Higgs 2010). Thus, identifying successful ageing, which presupposes freedom from disease and functional independence, as a major theme in newspaper depictions of nursing homes, where older adults receive substantial care and are functionally dependent, was unexpected. But our findings suggest that at least in the narrative sense the seemingly obvious markers such as nursing home residency no longer clearly delineate the Fourth Age from the Third Age if individuals retain essential control over the management of their life, the primary vehicle for which is maintaining one's financial independence and participation in the market economy.

Results indicate that successful ageing may be viewed as a continuous cultural process that extends into stories about nursing homes, a context traditionally viewed as emblematic of the Fourth Age. In contrast to prior research examining the ways in which the mass media talked about 
the 'young old' versus 'old old' (McHugh 2003), a more nuanced and subtle distinction of polarised ageism appears in portrayals of the nursing home sector. Here, those frail older persons who are acted upon as recipients of care and services and stripped of their adult agency are labelled 'dependent' and 'disposable'. On the other hand, those frail older persons with economic resources who continue to participate in the market economy are granted agency and viewed as more 'successful', 'independent' and 'relevant'.

The boundary between the Third and Fourth Ages is blurred with portrayals of frailty in the newspaper articles analysed having both physical/ mental and economic components. It is suggested that frailty that stems from wearing out of the body can be at least partially offset by the robustness of an individual's financial resources, and by continuing control over which those resources are put to use. If an older person is physically frail but is well off and not demented, they can continue to enjoy a lifestyle tailored to their preferences through buying customised services. Building a lifestyle and maintaining one's identity through uninhibited choices of consumption is the Third Age cornerstone (Gilleard and Higgs 2011). This finding about the ambiguity of media portrayals of frailty echoes other sociological research that used qualitative methods to advance conceptual understanding of frailty in later life as a liminal zone betwixt and between living and clinically recognised dying (Nicholson et al. 2012). It is in this zone that older adults are in a state of imbalance, experiencing progressive losses but simultaneously working on sustaining or even creating new connections with their physical and social environments (Nicholson et al. 2013). This dynamic reflects both the existential human dilemmas and the commodification of later life and a culture that values independence, productivity and individual responsibility for one's health and longevity.

Findings from the qualitative, interpretive component of our study complement and extend those published previously (Miller et al. 2012). While the quantitative content analysis revealed that the tone in the media portrayals of nursing homes was predominantly negative, and that content of the articles focused on financing and the quality of care in nursing homes, this paper revealed the meanings underlying these negative portrayals and the preoccupations with the economics of the nursing home industry, which revolve around two main themes. One is related to the management of lives considered to a certain extent disposable, as these frail individuals no longer have the agency or the resources to manage their own lives or to participate actively in broader society. The other theme emphasises the importance of financial autonomy in offsetting, to some extent, the debilitating effects of physical frailty. On the general level, this speaks to the issue of nursing homes' media 'face' constructed not only in negative terms, but also in 
positive or at least ambiguous terms, similar to what was found in another study that investigated how newspapers portrayed dementia through photographs of individuals expressing positive emotions and not only negative ones (Kessler and Schwender 2012).

A strength of the present study is that it included analysis of all articles about nursing homes published on the front pages of some of America's most widely circulated and influential newspapers over a ten-year period. The extended time frame of the study permitted us to identify profound and persistent stereotypes underlying the portrayal of nursing homes in the national media. The focus on articles published on the front page is an additional asset. Issues of ageing are rarely considered to be amongst the most newsworthy topics, with the media tending to under-represent ageing-related issues relative to other concerns (Turner 1991). It is reasonable to assume, however, that media representatives - in particular editors - considered the more than $15^{\circ}$ stories about nursing homes sufficiently important to give them such priority treatment. Furthermore, the discussions with research assistants who were young individuals aged 20-25 by means of which we elucidated and refined the themes and their narrative component provided further rigour to this study, as different team members brought their perspectives and knowledge to the table and helped us avoid possible idiosyncratic interpretations of the data.

As is the case for any sociological research, the findings from this study may be considered fully valid only in the context of the sample of articles studied. Whether the themes we uncovered in the course of our analyses may be present in articles about nursing homes published elsewhere in these four national newspapers, or published in other American newspapers, is a limitation of this study and may be the focus of future research. It would be instructive to examine the presence or absence of these and other themes over a longer period of time - to discern how universal the successful ageing discourse is, and what are its cultural, geographical, economic, temporal and other limits. It also would be instructive to conduct a cross-cultural study to compare the way frail older adults are portrayed in different societies - where use of nursing homes may or may not be as widespread as other forms of elder-care.

There is also an opportunity to analyse the article utilising other potentially useful techniques. For example, linguistic analysis could be used to further elucidate the language used to depict relatively poor and affluent nursing home residents over time. Another opportunity would be to focus on race in media representations to consider whether racial prejudices and stereotypes may skew or change the themes in terms of which nursing homes are portrayed. Future research could also extend the findings from this study by considering how stories about nursing homes are perceived by 
younger versus older adults residing in both community and institutional settings. Levy (2009) points out that ageing stereotypes may influence older adults' wellbeing; as such, it may be useful to learn whether and how stories about successful ageing in various contexts inspire older adults to make better choices in their lives or cause resentment and disappointment because they shine a light on their own inadequate choices. Still another avenue for future research could be to explore the perspectives of the reporters, columnists and editors who create stories about nursing homes and make decisions about placement. This would enable researchers to compare the intents of those who produced the stories, say, with respect to desired messages, with the readings and interpretations of lay people and researchers.

In sum, we found that depictions of nursing homes on the front pages of four major American newspapers are dominated by economic discourse, with nursing home residents being portrayed as 'objects' within society, turning only into 'subjects' in the case of individual economic resources. 'Objects' must be managed, albeit in an ethical and a humane way. But financial insolvency brings the costs of this management into serious consideration among those who provide the resources necessary to care for these nursing home residents. 'Subjects', by contrast, are the lucky ones who have the financial resources needed to retain the autonomy necessary to direct their own lives. They are the ones who are ageing successfully.

In our view, the study presented in this paper may be of particular interest to international readership because the general models of long-term care financing and service delivery prevalent in the USA also exist in other Western industrialised nations (Organisation for Economic Co-operation and Development 2005). Analysing American newspaper portrayals of nursing home residents, we uncovered emphasis on continued maintenance of individual purchasing power as a marker of staying in the Third Age. Our tentative proposition is that such findings may also be true in a broader Western context and not just specific to North America. This is due both to the value attached to money and to the ability to spend it, as a sign of individualism and as a dimension of personal agency. However, the degree to which maintenance of purchasing power may be viewed as a marker of successful ageing would most likely vary not only between Western societies and the rest of the world but also among different Western societies. Those residing in states with the social-democratic or Christian-democratic welfare systems may be more likely than their American counterparts to prefer paying a larger proportion of their income in taxes and delegating to society more responsibility for their wellbeing throughout the lifecourse. In these situations, purchasing power would be a lesser overall measure of 
individual's agency across all stages of the lifecourse, including later life, and thus less emphasis might be placed on retaining it.

Growing evidence suggests that wealth may be becoming an increasingly important consideration in later life in non-Western cultures as well. To a growing extent, even in these societies, older adults with greater wealth have more buffers against being at the charity of other individuals or the state. Such change is reflected, in part, in China where public policy (one-child families), population ageing and urban migration have contributed to the proliferation of private-sector facilities caring for older people, and many elders enter such facilities even when they have adult children (Feng et al. 2012). The result has been a concomitant shift away from almost exclusive reliance on public funding for the limited number of people who had previously used such institutions towards a more diverse array of revenue sources, including clients who pay privately. One can question whether 'managing disposable lives' and 'retaining purchasing power as successful ageing' will be emerging themes in media portrayals of nursing homes in nations where family care and/or public welfare was once the social norm, a virtue to be admired and upheld. It is our hope that this paper will start a fruitful academic exchange that will shine light on this and other relevant questions.

\section{Acknowledgements}

We would like to acknowledge the support of the following individuals for their invaluable assistance in conducting this research: Allison Cook, Rachel Goldstein, Dayanch Hojagyeldiyev, Betsy Jacobson, Corina Oala, Divya Samuel and Aaron Roberts. We also would like to thank participants of the Yale Centre for Cultural Sociology workshop and the session at the 2012 American Sociological Association conference, where earlier versions of this paper were presented, for their helpful comments and feedback. All views expressed in the paper are the authors' own. Funding for this research was provided in part by the National Institute of Ageing (grant number Po1-AG27296, Vincent Mor, Brown University, Principal Investigator), Killam Foundation and the Canadian Institutes for Health Research - Institute on Ageing. All three authors contributed to the analysis of the data, development of the conceptual argument and writing of the manuscript; the contributions of the first author were the most substantial as she took the lead in conducting this study and in writing the manuscript. None of the authors has any conflict of interest pertaining to this paper, the study it describes, or any information, person or organisations it refers to.

\section{References}

Atkinson, P. 2010. The contested terrain of narrative analysis - an appreciative response. Sociology of Health $\mathcal{E}$ Illness, 32, 4, 661-2. 
Audit Bureau of Circulations 2010. Circulation Averages for the Six Months Ended: 9/30/ 2oro. Available online at http://abcas3.accessabc.com/ecirc/newstitlesearchus. asp [Accessed 28 March 2011 ].

Baumgartner, F. R. and Jones, B. D. 1993. Agendas and Instability in American Politics. The University of Chicago Press, Chicago.

Benjamin, W. 1936. L'œuvre d'art à l'époque de sa reproduction méchanisée/The work of art in the age of mechanical reproduction. Zeitschrift für Sozialforschung Jahrgang V, Félix Alcan, Paris, 40-68.

Blakemore, S. 201 2. Media portrayal skews people's view of life in a residential home. Nursing Older People, 24, $1,7$.

Bowling, A. 2007. Aspirations for older age in the 21 st century: what is successful ageing? International Journal of Ageing and Human Development, 64, 3, 263-97.

Bytheway, B. 2005. Ageism and age categorisation. Journal of Social Issues, 61, 2, 361-74.

Chapman, S.A. 2005. Theorizing about aging well: constructing a narrative. Canadian Journal on Aging, 24, 1, 9-18.

Chivers, S. 2003. From Old Woman to Older Women: Contemporary Culture and Women's Narratives. Ohio State University Press, Columbus, Ohio.

Chivers, S. 2007. The silvering screen: age and trauma in Akira Kurasawa's Rhapsody in August. In Raoul, V., Canam, C., Henderson, A. and Paterson, C. (eds), Unfitting Stories: Narrative Approaches to Disability, Disease and Trauma. Wilfrid Laurier Press, Waterloo, Canada, 97-104.

Chivers, S. 2008. 'Move! You're in the way!' Disability and age meet on screen. Canadian Journal of Film Studies: Revue Canadienne D'Études Cinématographique, 17, 1, $30-43$.

Fairclough, N. 1995. Media Discourse. Edward Arnold, London.

Fairclough, N. 201 o. Critical Discourse Analysis: The Critical Study of Language. Pearson Education, Toronto.

Feng, Z., Liu, C., Guan, X. and Mor, V. 2012. China's rapidly aging population creates policy challenges in shaping a viable long-term care system. Health Affairs 31, $12,2764-73$.

Fisher, A. and Castle, N. 201 2. Why do nursing homes close? An analysis of newspaper articles. Social Work in Public Health, 27, 5, 409-23.

Fowler, R. 1991. Language in the News. Discourse and Ideology in the Press. Routledge, London.

Gilleard, C. and Higgs, P. 2007. Cultures of Ageing: Self, Citizen and the Body. Second edition, Prentice Hall, Harlow, UK.

Gilleard, C. and Higgs, P. 2010. Ageing without agency: theorizing the Fourth Age. Ageing E्F Mental Health, 14, 2, $121-8$.

Gilleard, C. and Higgs, P. 2011 . The third age as a cultural field. In Carr, D. C. and Komp, K. (eds), Gerontology in the Era of the Third Age: Implications and Next Steps. Springer, New York, 33-5o.

Hatch, L. R. 2005. Gender and ageism. Generations, 29, 3, 19-24.

Hilt, M. L. and Lipschultz, J. H. 2005. Mass Media, an Ageing Population, and the Baby Boomers. Lawrence Erlbaum, Mahwah, New Jersey.

Holstein, M. and Minkler, M. 2003. Self, society, and the 'New Gerontology'. Gerontologist, 43, 6, 787-97.

Jopp, D., Rott, C. and Oswald, F. 20o8. Valuation of life in old and very old age: the role of sociodemographic, social, and health resources for positive adaptation. Gerontologist, 48, 5, 646-58. 
Kessler, E.-M., Rakoczy, K. and Staudinger, U. 2004. The portrayal of older people in prime time television series: the match with gerontological evidence. Ageing $\mathcal{E}$ Society, 24, 4, 531-52.

Kessler, E.-M. and Schwender, C. 2012. Giving dementia a face? The portrayal of older people with dementia in German weekly news magazines between the years 2000 and 2009. Journals of Gerontology: Psychological Sciences and Social Sciences, 67, 2, 261-70.

Laliberte Rudman, D. 20o6. Shaping the active, autonomous and responsible modern retiree: an analysis of discursive technologies and their links with neo-liberal political rationality. Ageing $\mathcal{E}$ Society, 26, 2, 181-201.

Laslett, P. 1996. A Fresh Map of Life: The Emergence of the Third Age. Second edition, Macmillan Press, London.

Levy, B. 2oog. Stereotype embodiment: a psychosocial approach to ageing. Current Directions in Psychological Science, 18, 6, 332-6.

Martinson, M. 2007. Opportunities or obligations? Civic engagement and older adults. Generations, Winter, 3o, 4, 59-65.

Martinson, M. and Minkler, M. 2006. Civic engagement and older adults: a critical perspective. Gerontologist, 46, 3, 318-29.

McDaniel, S. A. 2005. Sentenced by a metaphor: living with aging. Recent Advances, Research Updates, 6, 3, 275-8.

McHugh, K. 2003. Three faces of ageism: society, image and place. Ageing E Society, 23, $2,165-85$.

Mebane, F. 2001. Want to understand how Americans viewed long-term care in 1998 ? Start with media coverage. Gerontologist, 41, 1, 24-33.

Miller, E., Tyler, D., Rozanova, J. and Mor, V. 2012. National newspaper portrayal of U.S. nursing homes: periodic treatment of topic and tone. Millbank Quarterly, 9o, $4,725^{-61 .}$

Minkler, M. and Fadem, P. 2002. 'Successful ageing': a disability perspective. Journal of Disability Policy Studies, 1 2, 4, 229-36.

Moody, H. 2008. The maturing of critical gerontology. Journal of Aging Studies, 22, 2, $205^{-9}$.

Neugarten, B.L. 1974. Age groups in American society and the rise of the young-old. Annals of the American Academy of Politics and Social Sciences, 415, $1,187-98$.

Nicholson, C., Meyer, J., Flatley, M. and Holman, C. 2013. The experience of living at home with frailty in old age: a psychosocial qualitative study. International Journal of Nursing Studies, 5o, 9, $1172-9$.

Nicholson, C., Meyer, J., Flatley, M., Holman, C. and Lowton, K. 2012 . Living on the margin: understanding the experience of living and dying with frailty in old age. Social Science and Medicine, 75, 8, 1426-32.

Organisation for Economic Co-operation and Development (OECD) 2005. Long-term Care for Older People. OECD, Paris.

Phoeniz, C., Smith, B. and Sparkes, A. 2010. Narrative analysis in aging studies: a typology for consideration. Journal of Aging Studies, 24, 1, 1-1 1.

Pifer, A. and Bronte, L. (eds) 1986. Our Aging Society: Paradox and Promise. W. W. Norton, New York.

Rowe, J. and Kahn, R. 1998. Successful Aging. Random House, New York.

Rozanova, J. 2006. Newspaper portrayals of health and illness among Canadian seniors: who ages healthily and at what cost? International Journal of Ageing and Later Life, 1, 2, 111 1-39.

Rozanova, J. 2010. Discourse of successful aging in The Globe $\mathcal{E}^{2}$ Mail: insights from critical gerontology. Journal of Aging Studies, 24, 4, $213^{-22 .}$ 
Rozanova, J., Dosman, D. and De Jong Gierveld, J. 2008. Participation in rural contexts: community matters. In Keating, N. (ed.), A Good Place to Grow Old? Critical Perspectives on Rural Ageing. Policy Press, Bristol, UK, 75-86.

Rozanova, J., Northcott, H. and McDaniel, S. A. 2006. Seniors and portrayals of intragenerational and inter-generational inequality in The Globe $\mathcal{E}^{2}$ Mail. Canadian Journal on Aging, 25, 4, 373-86.

Sinding, C. and Gray, R. 2005. Active aging - spunky survivorship? Discourses and experiences of the years beyond breast cancer. Journal of Aging Studies, 19, 2, 147-61.

Spector-Mersel, G. 2006. Never-aging stories: Western hegemonic masculinity scripts. Journal of Gender Studies, 15, 1, 67-82.

Thompson, E. H. and Whearty, P. M. 2004. Older men's social participation: the importance of masculinity ideology. Journal of Men's Studies, 13, 1, 5-24.

Tulle, E. 2008. Acting your age? Sports science and the aging body. Journal of Aging Studies, 22, 4, 340-7.

Turner, B. 1991. Ageing, status politics and sociological theory. British Journal of Sociology, 4o, 4, $5^{88-606 .}$

Ulsperger, J. 2002. Geezers, greed, grief, and grammar: frame transformation in the nursing home reform movement. Sociological Spectrum, 22, 4, 385-406.

van Dijk, T.A. 1997. The study of discourse. In van Dijk, T.A. (ed.), Discourse as Structure and Process: Discourse Studies: A Multidisciplinary Introduction. Sage, Thousand Oaks, California, 1-34.

van Dijk, T. A. 2006. Discourse and manipulation. Discourse $\mathcal{E}$ Society, 17, 3, 359-83. Wetherell, M., Taylor, S. and Yates, S. 2001. Discourse as Data: A Guide for Analysis. Sage, London.

Whitfield, C. 2001. Benign or malign? Media stereotyping. Nursing Older People, 13, 6 , $10-13$.

Accepted I I July 2OI4; first published online 5 September 2014

Address for correspondence:

Julia Rozanova, Department of Sociology,

Yale University, P.O. Box 208265,

New Haven, CT o6520-8265, USA.

E-mail: julia.rozanova@yale.edu 